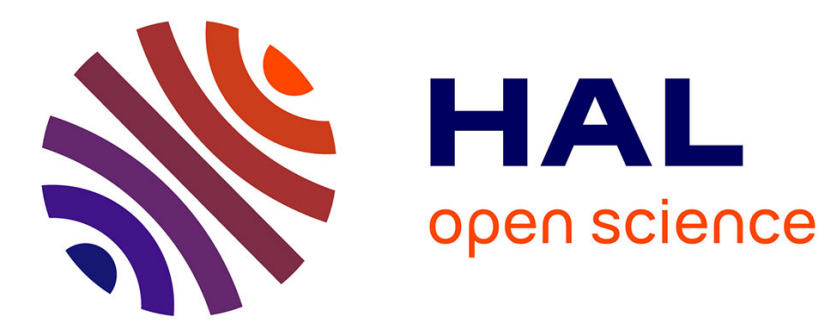

\title{
Should the Carbon Price Be the Same in All Countries?
}

Antoine d'Autume, Katheline Schubert, Cees Withagen

\section{To cite this version:}

Antoine d'Autume, Katheline Schubert, Cees Withagen. Should the Carbon Price Be the Same in All Countries?. Journal of Public Economic Theory, 2016, 10.1111/jpet.12162 . halshs-01300261

\section{HAL Id: halshs-01300261 https://shs.hal.science/halshs-01300261}

Submitted on 9 Apr 2016

HAL is a multi-disciplinary open access archive for the deposit and dissemination of scientific research documents, whether they are published or not. The documents may come from teaching and research institutions in France or abroad, or from public or private research centers.
L'archive ouverte pluridisciplinaire HAL, est destinée au dépôt et à la diffusion de documents scientifiques de niveau recherche, publiés ou non, émanant des établissements d'enseignement et de recherche français ou étrangers, des laboratoires publics ou privés. 


\title{
Should the carbon price be the same in all countries?
}

\author{
Antoine d'Autume, Katheline Schubert* \\ Paris School of Economics, University Paris 1 Panthéon-Sorbonne \\ Cees Withagen \\ VU University Amsterdam
}

\begin{abstract}
International differences in fuel taxation are huge, and may be justified by different local negative externalities that taxes must correct, as well as by different preferences for public spending. In this context, should a worldwide uniform carbon tax be added to these local taxes to correct the global warming externality? We address this question in a second best framework à la Ramsey, where public goods have to be financed through distortionary taxation and the cost of public funds has to be weighted against the utility of public goods. We show that when lump-sum transfers between countries are allowed for, the second best tax on the polluting good may be decomposed into three parts: one, country-specific, dealing with the local negative externality, a second one, country-specific, dealing with the cost of levying public funds, and a third one, global, dealing with the global externality and which can be interpreted as the carbon price. Our main contribution is to show that the uniformity of the carbon price should still hold in this second best framework. Nevertheless, if lump-sum transfers between governments are impossible to implement, international differentiation of the carbon price is the only way to take care of equity concerns.
\end{abstract}

keywords: carbon price, second best, Pigovian taxation

\section{Introduction}

The virtues of a uniform carbon price, taking the form of a world carbon tax or being the result of a world emission permits market, are well recognized. A uniform carbon price, reflecting the true social cost of emissions, is the best incentive to curb all negative externalities associated with fossil fuel consumption and global warming. Uniformity of the price implies the equalization of marginal abatement costs and therefore minimizes the worldwide cost of abatement of emissions. The redistribution of tax receipts or the initial allocation of permits then offers the possibility to accompany carbon taxation with an international redistribution scheme and to share equitably the burden of taxation between countries. This optimistic picture is often questioned in the name of realism.

${ }^{*}$ We thank Julien Daubanes, Pierre Lasserre, Stéphane Gauthier, and especially Roger Guesnerie for useful discussions. Antoine d'Autume and Katheline Schubert acknowledge the support of the French National Research Agency (ANR) under the CLEANER project (ANR_NT09_505778). Cees Withagen gratefully acknowledges financial support from FP7-IDEAS-ERC Grant No. 269788. 
Existing differences in national energy taxation, especially fuel taxation, are considerable (see Table 1). The question that arises is whether we should consider such taxes as implicit carbon taxes and therefore abstain from super-imposing a specific carbon tax.

Table 1: Excise on premium unleaded gasoline in some OECD countries, 2012 (\% of the consumer price)

\begin{tabular}{|ccccccccc|}
\hline Germany & Denmark & United States & Finland & France & Italy & Japan & United Kingdom & Sweden \\
39.0 & 33.9 & 13.1 & 37.9 & 37.3 & 40.1 & 38.1 & 40.6 & 36.6 \\
\hline
\end{tabular}

Source: IEA Statistics, Energy prices and taxes, 2013

Moreover, is it really possible to use the allocation of tax receipts or emission quotas to alter substantially the world distribution of income? First of all, a consequence of using a quota allocation mechanism is clearly that the implied lump-sum transfers to local governments are restricted to be positive. Second, will governments even accept to depart from the simple rule that each country should be paid back exactly the amount of taxes it paid or the value of the permits it had to buy? If international transfers are so restricted, isn't it preferable to allow poor countries to face a lower carbon price? Chichilnisky and Heal (1994) put forward such an argument against the international equalization of abatement costs and suggested that a lower effort should be required from poor countries. Shiell (2003) followed up on this idea and in particular characterized the set of second best optimal allocations when intercountry transfers are restricted to be positive or to be exactly equal to the sums paid to the world regulator. Sandmo (2005) also pointed out that the carbon price must be uniform if perfect international transfers are possible, but should be differentiated when they are not, to reflect redistributive concerns.

A proper analysis of these issues requires a clarification of the purpose of existing fuel taxes in the first place. If no clear economic reason may be invoked for their existence, adding to them a uniform carbon price has no chance to appear optimal. However, if existing taxes are, in some sense, already fixed at an optimum level, adding a common tax to curb global warming may be warranted. Existing fuel taxation has two prime objectives. The first one is to counter local externalities independently of global warming. For example, burning of fossil fuel contributes to global warming through $\mathrm{CO}_{2}$ emissions, but also leads to $\mathrm{SO}_{2}$ and particulate matters emissions, which have a local effect. The second objective of fuel taxation is that it offers governments an easy way to levy funds and finance the provision of public goods. The French gasoline tax, the so-called TICE (Taxe Intérieure sur la Consommation d'Energie), an excise tax currently fixed at 0.61 euros per liter, has indeed been created taking explicitly into account the two objectives of reducing negative externalities associated with fuel consumption by cars and of providing means to finance highway construction.

International differences in fuel taxation may a priori be justified by different local negative externalities that taxes must correct, as well as by different preferences for public spending in the different countries. In this context, should a worldwide uniform carbon tax, or emission permit price, be added to these optimal local taxes? This is the question we consider.

Addressing seriously the financing of public goods provision necessitates a second best approach. Public goods have to be financed through distortionary taxation and the cost of these distorsions, i.e., the cost of levying public funds, has to be weighted against the utility of public goods. On the other hand, Pigovian taxes, aiming at reducing negative 
externalities, and (distortionary) taxes, aiming at financing the provision of public goods, are to some extent substitutes. A Pigovian tax required to decrease emissions is also a means to finance public spending. Inversely, a negative externality associated with the production of a commodity decreases the cost of public funds associated with the use of this good as a tax-base. The negative impact of the distortions associated with taxation are mitigated by the reduction of the negative externality. Sandmo (1975) initiated this kind of analysis in a one-country case.

In this paper, we extend the Chichilnisky and Heal (1994) and Sandmo (2005) models by introducing local externalities and public goods. We consider a clean consumption good, a dirty consumption good, source of both local externalities and global warming, and a public good. The three goods may be produced in each country from a given endowment of a generic good. There is no international trade and countries interact only through global emissions. These assumptions are made mainly for the sake of a clear presentation of the results. The main message will not be affected by including more realistic production technologies.

We first examine first best optimal allocations and show that they can be implemented by a world regulator through country-specific emission taxes and lump-sum transfers to consumers, possibly negative. The pollution tax consists of two parts, one dealing with the local externality and another one dealing with the global externality. The latter part is uniform across countries. This suggests a more decentralized implementation. Local governments then levy a tax correcting the local externality, are in charge of the provision of the local public good, and tax or subsidize their consumers in a lump-sum way. An international environmental agency collects the uniform global pollution tax and makes lump-sum (positive or negative) transfers to local governments, thus taking international equity concerns into account. This implementation assumes passive local governments, who do not take advantage of the influence they might have on the world carbon price and the levels of international transfers. Basically, this preliminary analysis confirms the optimistic view which we described above. In a first best setting, the uniformity of the carbon tax should be the rule, provided local governmental decisions are taken in an optimal way.

We then consider a more realistic second best framework. We follow the standard Ramsey approach and assume that governments cannot tax consumers in a lump-sum way. If necessary they have to rely on distortionary taxation to finance public good provision. We show that the second best taxes on the polluting good may be decomposed into three parts: one, country-specific, dealing with the local pollution externality, a second one, country-specific, dealing with the marginal cost of levying public funds, and a third one, global, dealing with the global externality. Our main contribution is to show that uniformity of the carbon price should still hold in this second best framework. This is a striking result as we know since Lipsey and Lancaster (1956-7) that rules which are optimal in a first best world generally fail to be so in a second best world.

To get a better understanding of this result we show that a true decentralization of the second best optimum may be obtained. The international environmental agency fixes a common carbon tax or controls emissions through a permits market, and distributes lump-sum transfers to local governments. Each of these is then free to deal as it wishes with local externalities and distortionary taxation needed to finance the provision of local public goods. This result supports, in a somewhat general setting, Tirole's (2009) proposal to base climate policy upon a world permits market, leaving each country free to choose whatever instrument it wants to meet its emission target. This result relies 
on the feasibility of arbitrary lump-sum transfers between countries, which takes us back to the Chichilnisky and Heal (1994) and Sandmo (2005) analysis. This assumption is debatable.

Let us first point out that the impossibility of lump-sum taxation of consumers, which is at the core of the Ramsey approach, cannot be readily extended to the case of countries or local governments. In the case of consumers, this impossibility is justified by information problems. Personalized lump-sum transfers are impossible because governments lack the necessary information about individual characteristics. The Ramsey approach then simply assumes away the possibility to levy a lump-sum tax on consumers, thus offering a useful short-cut to analyze a situation where distortionary taxation is required. Sandmo (2000), among others, provides such a defense. On the contrary, the impossibility to implement arbitrary lump-sum transfers between governments cannot be motivated by information problems. Intercountry transfers have indeed been part of the first Kyoto negociations, in the form of asymmetric quotas allocations favoring developing countries, and received new support at the Cancun United Nations Framework Convention on Climate Change conference in December 2010, where a Green Climate Fund has been established to assist developing countries in the financing of their climate policies.

Intercountry transfers thus appear a priori feasible. However, they face political economy objections. Governments know that their citizens would probably object to sizable transfers to other governments. The assumption of no intercountry transfers may then appear realistic, and we also examine its consequences. As the receipts of the world carbon tax, or the revenues of the sale of the permits, have to be redistributed, the no intercountry transfers assumption can be rephrased as the condition that each country should receive a positive lump-sum transfer precisely equal to the amount of carbon taxation paid by its citizens. We examine in a last section the optimum under this assumption, called third best optimum. We thus revert to the Chichilnisky and Heal (1994) result. In such a framework, international differentiation of the carbon price is the only way to take care of equity concerns. Poorer countries should probably pay a lower carbon tax. However, this result may be put in perspective. The redistributive gains of such a differentiation of carbon taxes may be small. A substantial amount of redistribution would then be at the cost of an important loss of efficiency.

We restrict our analysis to the case of local governments which are passive in the sense that they take as given the world carbon price and the transfers they receive from the international environmental agency. Verbon and Withagen (2010) consider on the contrary the case of active local governments who act strategically as they understand that their behavior affects the world carbon price. In a rather general framework, they show that a proper initial allocation of permits may counter strategic behavior and thus lead to a Pareto efficient allocation. Ogawa and Wildasin (2009) follow a different route and show that local government decisions may, in a very special case, produce a Paretoefficient outcome.

\section{The model}

We consider $n$ countries $(n \geq 2)$, indexed by $i=1,2, \ldots, n$. There is a representative consumer in each. Each country has an endowment $Y_{i}$ of a generic good. This good may be used to produce, one for one, a private clean good, a local non-polluting public good and a private polluting good. Pollution is both local and global and encompasses country-specific pollution and greenhouse emissions contributing to global warming. We 
denote by $C_{i}, G_{i}$ and $X_{i}$ consumption of the three goods by the representative consumer in each country. Pollution is denoted by $Z_{i}$. The polluting good is scaled in such a way that $Z_{i}=X_{i}$. World pollution is denoted by $Z_{w}=Z_{1}+Z_{1} \ldots+Z_{n}=X_{1}+X_{2} \ldots+X_{n}=X_{w}$. By $X$ we denote the vector $\left(X_{1}, X_{2}, \ldots, X_{n}\right)$. The vectors $C, Y, G$ and $Z$ are defined in a similar way.

There is no international trade. Each country consumes its production of the three goods and only interacts with others through its contribution to global warming. International transfers of the non-polluting consumption good will be possible, however. The production side of the model is highly simplified, all marginal costs of production being basically equal to one, in terms of the generic good. These simplifications do not affect our main results.

The utility function of the representative consumer in jurisdiction $i$ is

$$
U^{i}\left(C_{i}, X_{i}, G_{i}, Z_{i}, Z_{w}\right)
$$

We assume $U_{C}^{i}, U_{X}^{i}, U_{G}^{i}>0, U_{Z}^{i}, U_{Z_{w}}^{i}<0$. Here $U_{C}^{i}$ is the partial derivative with respect to $C_{i}$ and the other expressions have a similar meaning. Moreover, we assume that the utility function satisfies the usual conditions such as differentiability, concavity in $(C, X, G)$, convexity in $\left(Z, Z_{w}\right)$ and, in maximization processes, allows for interior solutions.

\section{First best}

\subsection{The social optimum and its implementation}

A first best Pareto optimum may be characterized as a feasible allocation which maximizes a weighted sum of individual utilities, since we can identify countries and their representative consumers. Under convexity assumptions, varying the weights provides an easy way to describe the whole set of Pareto optima. The weights may be interpreted as the derivatives of a social utility function having individual utility levels as arguments.

Let $\beta=\left(\beta_{1}, \beta_{2}, \ldots, \beta_{n}\right)$ be the weights attached to the utilities of the representative consumer in each country. A first best Pareto optimum is a solution of the following problem:

$$
\max \sum_{i=1}^{n} \beta_{i} U^{i}\left(C_{i}, X_{i}, G_{i}, X_{i}, X_{w}\right)
$$

subject to the resource constraint

$$
\sum_{i=1}^{n} Y_{i} \geq \sum_{i=1}^{n}\left(C_{i}+X_{i}+G_{i}\right)
$$

and non-negativity conditions. Under mild non-satiation conditions, the resource constraint (3) is binding at a Pareto optimum.

Proposition 1 A first best Pareto optimum is characterized by the following conditions:

$$
\begin{gathered}
\beta_{1} U_{C}^{1}=\ldots=\beta_{i} U_{C}^{i}=\ldots=\beta_{n} U_{C}^{n} \\
\frac{U_{G}^{i}}{U_{C}^{i}}=1, \quad i=1,2, \ldots, n \\
\frac{U_{X}^{i}}{U_{C}^{i}}+\frac{U_{Z}^{i}}{U_{C}^{i}}+\sum_{j=1}^{n} \frac{U_{Z_{w}}^{j}}{U_{C}^{j}}=1, \quad i=1,2, \ldots ., n
\end{gathered}
$$


The proof of this proposition is in the appendix, as well as the proofs of all other propositions.

The three sets of conditions (4)-(6) and the resource constraint (3) jointly determine optimal levels of production of all goods. Conditions (5) and (6) are efficiency conditions which do not depend on the social weights $\beta$ attached to the various consumers. They state that the consumers' marginal rate of substitution (MRS) between the three goods should be equal to one, namely their relative production costs. The MRS between the polluting good $X_{i}$ and the non-polluting good $C_{i}$ takes into account the negative damages the consumption of the polluting good creates, both locally and worldwide, through global warming. These damages are evaluated in terms of the private non-polluting good. Condition (4) selects a particular Pareto optimum, depending on the social weights attached to individual consumers by the world central planner. It shows that weighted marginal utilities derived from clean consumption should be equalized across consumers/countries.

Let us now see how this Pareto optimum may be implemented. We assume that a world regulator is in charge of the control of local and global externalities and of public goods provision. Local governments play no role at this stage. Without loss of generality, we assume that clean consumption is not taxed. The world regulator imposes pollution taxes $\theta_{i}(i=1,2, \ldots, n)$ that may differ accross consumers, finances all public spending $G_{i}$ and makes direct positive or negative transfers $T_{c i}$ to consumers.

Budget constraints of the consumers and the world regulator are respectively:

$$
\begin{aligned}
C_{i}+\left(1+\theta_{i}\right) X_{i} & =Y_{i}+T_{c i}, \quad i=1,2, \ldots, n \\
\sum_{i=1}^{n} \theta_{i} X_{i} & =\sum_{i=1}^{n}\left(G_{i}+T_{c i}\right)
\end{aligned}
$$

The representative consumer of country $i$ maximizes utility under the budget constraint (7), taking public spending $G_{i}$ and pollution levels $Z_{i}$ and $Z_{w}$ as given. The optimality condition is:

$$
\frac{U_{X}^{i}}{U_{C}^{i}}=1+\theta_{i}, i=1,2, \ldots, n
$$

Comparison with (6) shows that optimality requires tax rates equal to:

$$
\theta_{i}=-\frac{U_{Z}^{i}}{U_{C}^{i}}-\sum_{j=1}^{n} \frac{U_{Z_{w}}^{j}}{U_{C}^{j}}, \quad i=1,2, \ldots, n
$$

with quantities taken at the optimum. The additivity property in this formula suggests to decompose each tax rate into a local component, equal to the local marginal damage, and a common global one, equal to the sum of all worldwide marginal damages resulting from global warming:

$$
\theta_{i}=\phi_{i}+\tau, \quad \phi_{i}=-\frac{U_{Z}^{i}}{U_{C}^{i}}, \quad \tau=-\sum_{j=1}^{n} \frac{U_{Z_{w}}^{j}}{U_{C}^{j}}
$$

With these Pigovian taxes, condition (9) states that the price of the polluting good, for the consumer, is equal to its true marginal cost, including its own marginal production cost, equal to one, and marginal environmental costs. Optimality also requires proper levels of provision of public goods, according to condition (5). Finally, lump-sum transfers $T_{c i}$ are used to reach a specific Pareto optimum, characterized by the weights $\beta_{i}$ s attached 
to each country. These transfers may be positive or negative. In the case where first best Pigovian tax receipts are sufficient to finance all first best public spendings,

$$
\sum_{i=1}^{n} \theta_{i} X_{i} \geq \sum_{i=1}^{n} G_{i}
$$

the world regulator's budget constraint (8) shows that the sum of feasible transfers to consumers is positive. All of them may be positive. If not, at least one consumer must receive a negative transfer.

\subsection{Decentralization: an international environmental agency, local governments and consumers}

The previous decomposition of the taxes on the polluting good suggests that the optimal allocation may be obtained in a decentralized setting, where local governments impose local taxes, aimed at correcting local externalities, while a global (carbon) tax is implemented at the world level by an international environmental agency. We may then assume that the environmental agency redistributes the receipts of the carbon tax to local governments rather than to consumers.

Consumer budget constraints are still (7), with $\theta_{i}=\phi_{i}+\tau$. The consumer pays a $\operatorname{tax} \phi_{i}$ to the local government and a $\operatorname{tax} \tau$ to the environmental agency. Let $T_{i}$ be the transfer from the environmental agency to local government $i$. The local governments' budget constraints are

$$
G_{i}+T_{c i}=\phi_{i} X_{i}+T_{i}
$$

where $T_{c i}$ is now the transfer from governement $i$ to its consumer, while the environmental agency's budget constraint is

$$
\sum_{i=1}^{n} T_{i}=\tau \sum_{i=1}^{n} X_{i}
$$

Carbon tax receipts are redistributed to local governments. Each of them uses the revenues, together with local tax receipts, to finance local public goods provision and lump-sum transfers to its consumers. Nothing prevents transfers $T_{i}$ and $T_{c i}$ from being negative.

From (7) and (12) we obtain country budget constraints:

$$
C_{i}+G_{i}+(1+\tau) X_{i}=Y_{i}+T_{i}, i=1,2, \ldots, n
$$

They can be written as

$$
T_{i}=\tau X_{i}+\left(C_{i}+G_{i}+X_{i}-Y_{i}\right), i=1,2, \ldots, n
$$

which shows that each transfer to a government includes the redistribution of the world taxes levied on the country and an additional term taking care of the desired redistribution between countries.

The conclusion of this exercise is that differences in local energy taxes do not refute the uniformity of the carbon tax, provided that local taxes are optimally designed to counter local externalities. This result is natural in a first best setting where lump-sum transfers may be freely implemented between countries and consumers. The issue is to see whether this result still holds in a second best setting. 


\section{Second best}

We follow the Ramsey optimal taxation approach and assume that it is not possible to make negative transfers to consumers. The world regulator in the centralized setting, or the local governments in the decentralized setting, are unable to levy lump-sum taxes on consumers, and must instead resort to distortionary taxation, if needed. The new constraint is simply that lump-sum transfers $T_{c i}$ have to be non-negative.

As was first shown by Sandmo (1975) in a one-country framework, the presence of externalities modifies the optimal tax scheme. If Pigovian taxation receipts are sufficient to finance public good provision and the desired redistribution is limited, the first best allocation is attainable. Tax receipts are able to finance public goods provision and some positive lump-sum transfers to consumers. If not, additional distortionary taxation is required and we switch to a second best situation.

In our framework, the non-negativity of transfers to consumers takes the following form, which follows from (7):

$$
C_{i}+\left(1+\theta_{i}\right) X_{i} \geq Y_{i}, \quad i=1,2, \ldots, n
$$

\subsection{The second best optimum and its implementation}

A world regulator is again in charge of all public decisions. Formally, the problem is to maximize (2) under the resource constraint (3) and the additional incentive constraint

$$
\left(C_{i}-Y_{i}\right)+X_{i} \frac{U_{X}^{i}\left(C_{i}, X_{i}, G_{i}, X_{i}, X_{w}\right)}{U_{C}^{i}\left(C_{i}, X_{i}, G_{i}, X_{i}, X_{w}\right)} \geq 0, i=1,2, \ldots, n
$$

This is a so-called primal version of constraint (16), where we use the consumer's optimality condition (9) to eliminate the tax rate.

Let us define $H^{i}\left(C_{i}, X_{i}, G_{i}, X_{i}, X_{w}\right)$ as the left-hand side of (17), and denote $H_{C}^{i}$ the partial derivative of $H^{i}$ with respect to $C_{i}$, the other expressions $\left(H_{G}^{i}, H_{X}^{i}, H_{Z}^{i}, H_{Z_{w}}^{i}\right)$ having a similar meaning. Let us also denote $\widetilde{\mu}_{i}$ the Lagrange multiplier associated to constraint (17), and $\mu_{i}=\widetilde{\mu}_{i} / \beta_{i}$. We have the following proposition:

Proposition 2 A second best Pareto optimum is characterized by the following conditions:

$$
\begin{gathered}
\beta_{1}\left(U_{C}^{1}+\mu_{1} H_{C}^{1}\right)=\ldots=\beta_{n}\left(U_{C}^{n}+\mu_{n} H_{C}^{n}\right) \\
\frac{U_{G}^{i}+\mu_{i} H_{G}^{i}}{U_{C}^{i}+\mu_{i} H_{C}^{i}}=1, \quad i=1,2, \ldots, n \\
\frac{U_{X}^{i}+\mu_{i} H_{X}^{i}}{U_{C}^{i}+\mu_{i} H_{C}^{i}}+\frac{U_{Z}^{i}+\mu_{i} H_{Z}^{i}}{U_{C}^{i}+\mu_{i} H_{C}^{i}}+\sum_{j=1}^{n} \frac{U_{Z_{w}}^{j}+\mu_{j} H_{Z_{w}}^{j}}{U_{C}^{j}+\mu_{j} H_{C}^{j}}=1, \quad i=1,2, \ldots, n
\end{gathered}
$$

The conditions for a Pareto optimum of Proposition 1 must be adjusted to take into account the impossibility to finance public goods through a lump-sum tax on consumers. Variable $\mu_{i}$ is the cost of levying public funds on individual $i$ or, more precisely, the cost of being unable to levy a lump-sum tax on the representative consumer in country $i$. These funds may be used to finance public goods or simply to redistribute income. $\mu_{i}$ is equal to zero if the world regulator wishes instead to make a direct positive transfer $T_{c i}$ to consumer $i$. It might be the case that the world regulator wishes to do so for all 
consumers. This occurs if, on the one hand, tax receipts from strictly Pigovian taxes (the first best taxes) prove sufficient to finance all the desired public goods and, on the other hand, the world regulator is satisfied with redistributing the excess as positive lump-sum taxes to all consumers, as he/she does not want to alter too much the world distribution of income. In such a case all $\mu_{i}$ s are zero and the second best optimality conditions reduce to the first best ones. This is a very special case however. A more plausible case is the one where some, or all, $\mu_{i} \mathrm{~s}$ are positive. First best conditions must then be adjusted to take into account the costs of levying public funds.

A special case is the one where the utility functions (1) are separable and quasi-linear in $C_{i}$. Then $U_{C}^{i}$ equals unity and the cross derivatives are nil, which implies $H_{C}^{i}=1$, $H_{G}^{i}=H_{Z}^{i}=H_{Z_{w}}^{i}=0$ and $H_{X}^{i}=U_{X}^{i}+X_{i} U_{X X}^{i}$. The first two optimality conditions reduce to

$$
\begin{gathered}
\beta_{1}\left(1+\mu_{1}\right)=\ldots=\beta_{n}\left(1+\mu_{n}\right) \\
U_{G}^{i}=1+\mu_{i}
\end{gathered}
$$

Public goods provision must be pushed in each country to the level where the marginal utility of public goods equals their production cost, here equal to one, augmented by the cost $\mu_{i}$ of levying public funds. Moreover, optimal international redistribution requires the equality of the weighted overall costs of public goods $\beta_{i}\left(1+\mu_{i}\right)$.

The three sets of conditions (18)-(20), together with the resource constraint (3) and incentive constraints (17) determine the second best optimum. (19) and (20) are efficiency conditions which do not depend on the social weights $\beta$. Condition (18) selects a particular optimum, depending on $\beta$.

From these necessary conditions we can retrieve the second best optimal pollution $\operatorname{tax} \theta_{i}$ and obtain, thanks to the additive structure of formula (20), a meaningful decomposition of this tax rate. It follows from (9) that $U_{X}^{i}=\left(1+\theta_{i}\right) U_{C}^{i}$. Then we have the following:

Corollary 3 In a second best setting, the carbon tax is unique. The overall tax on the polluting good may be decomposed in the sum of two local taxes and one global tax:

$$
\theta_{i}=\phi_{i}+\psi_{i}+\tau
$$

with

$$
\phi_{i}=-\frac{U_{Z}^{i}+\mu_{i} H_{Z}^{i}}{U_{C}^{i}+\mu_{i} H_{C}^{i}}, \quad \psi_{i}=\mu_{i} \frac{\frac{U_{X}^{i}}{U_{C}^{i}} H_{C}^{i}-H_{X}^{i}}{U_{C}^{i}+\mu_{i} H_{C}^{i}}, \quad \tau=-\sum_{j=1}^{n} \frac{U_{Z_{w}}^{j}+\mu_{j} H_{Z_{w}}^{j}}{U_{C}^{j}+\mu_{j} H_{C}^{j}}
$$

$\operatorname{Tax} \phi_{i}$ is a Pigovian tax on local pollution. Tax $\psi_{i}$ is a Ramsey tax acting as a substitute to the impossibility of levying lump-sum taxes on consumers. Finally, tax $\tau$ is a world carbon tax needed to curb greenhouse gas emissions. If the optimal second best allocation is such that the incentive constraint (17) is not binding in country $i$, the cost of levying public funds $\mu_{i}$ is equal to zero, the Pigovian tax $\phi_{i}$ has the same expression as at the first best (see (11)), and the Ramsey tax $\psi_{i}$ is equal to zero.

The striking result here is that the carbon $\operatorname{tax} \tau$ is uniform: it is the same for all countries involved. This result, natural in a first best setting, is more surprising in a second best framework, where optimal rules are usually quite different from what they would be at the first best. The virtues of a uniform carbon tax and its ability to provide 
proper incentives are much less compelling when specific constraints preexist and unavoidably introduce many distortions in the economy. Differentiated carbon prices might then appear as a useful compromise between efficiency and equity. Sandmo (2005) asks exactly the same question as we do: "Should one design compensatory transfers [between rich and poor countries], or should the design of the environmental taxes themselves have built-in distributional elements?" (pp. 121) ${ }^{1}$. Our result is that the design of the carbon tax must not include distributional elements. Those are taken care of by the lump-sum international transfers implicitly present in our setting, through the assumption that the resource constraint (3) is global ${ }^{2}$, and through the local Ramsey taxes $\psi_{i}$.

To be still more precise about the meaning of our result, let us consider the case where there are neither public spending nor local externalities. We now have a model stripped of any local element, and the issue of the uniformity of the carbon tax is posed in a perfectly clear way. The Pigovian tax $\phi_{i}$ is obviously nil, as there is no local externality. It is easy to see that the Ramsey tax $\psi_{i}$ is not, and has the same formal expression as in the general case. Now, its only objective is to take care of equity issues, and it is different for the consumers belonging to different countries. The tax rate $\tau$ aimed at fighting the global externality also has the same formal expression as in the general case. The overall tax on the polluting good $\theta_{i}=\psi_{i}+\tau$ is differentiated among countries, but the Pigovian part $\tau$ is common (see Table 2, but ignore the Third best entry for the time being). The world regulator perceives the optimality of having a uniform carbon tax $\tau$, but he/she also wants to finance in an equitable way the distribution of lump-sum transfers to the poorest consumers. This is done by imposing different $\psi_{i}$ components in the overall tax.

Table 2: No local externalities and public goods

First best

$\beta_{1} U_{C}^{1}=\ldots=\beta_{n} U_{C}^{n} \quad \theta=\tau \quad \tau=-\sum_{j=1}^{n} \frac{U_{Z_{w}}^{j}}{U_{C}^{j}}$

Second best

$\beta_{1}\left(U_{C}^{1}+\mu_{1} H_{C}^{1}\right)=\ldots=\beta_{n}\left(U_{C}^{n}+\mu_{n} H_{C}^{n}\right) \quad \theta_{i}=\psi_{i}+\tau \quad \psi_{i}=\mu_{i} \frac{\frac{U_{X}^{i}}{U_{C}^{i}} H_{C}^{i}-H_{X}^{i}}{U_{C}^{i}+\mu_{i} H_{C}^{i}} \quad \tau=-\sum_{j=1}^{n} \frac{U_{Z_{w}}^{j}+\mu_{j} H_{Z_{w}}^{j}}{U_{C}^{j}+\mu_{j} H_{C}^{j}}$

Third best

$\beta_{1}\left(U_{C}^{1}-U_{X}^{1}\right)=\ldots=\beta_{n}\left(U_{C}^{n}-U_{X}^{n}\right) \quad \theta_{i}=\tau_{i} \quad \tau_{i}=-\frac{\sum_{j=1}^{n} \beta_{j} U_{Z_{w}}^{j}}{\beta_{i} U_{C}^{i}}$

We may compare these results with the ones obtained by Sandmo (1975). We keep local elements out but replace them by a unique global public good, as in Sandmo (1975) and assume, as he does, that the desired quantity of this global public good is given. No change has to be made in our formulas, apart from the fact that the amount of global public good appears in the resource constraint. Sandmo considers heterogeneous consumers in a one-country framework. He of course assumes that the tax rate $\theta$ on the polluting good has to be unique. In our multi-country framework, we show that the world regulator should indeed use the possibility of differentiating this tax among different countries.

\footnotetext{
${ }^{1}$ The framework Sandmo (2005) uses is a two-country model of a structure close to ours but without local externalities and local public goods. He studies the first best solution of the model, but not the second best, in the sense we have given to this term (no negative transfers to consumers).

${ }^{2}$ For country $i$, these transfers are simply $C_{i}+G_{i}+X_{i}-Y_{i}$.
} 


\subsection{Decentralization: the subsidiarity principle}

The previous results may be clarified if we introduce a two-level regulation. An international environmental agency sets the world carbon $\operatorname{tax}^{3}$, and distributes transfers to local governments. Each of these is then free to deal as it wishes with local externalities and distortionary taxation needed to finance the provision of local public goods.

The budget constraint (12) of local government $i$ which was relevant in the case of the first best, must be adapted to take into account the local Ramsey taxes $\psi_{i}$. Government $i$ 's budget constraint now is:

$$
G_{i}+T_{c i}=\left(\phi_{i}+\psi_{i}\right) X_{i}+T_{i}, \quad T_{c i} \geq 0
$$

The environmental agency collects the carbon tax imposed on consumers in each country and redistributes the receipts as lump-sum transfers $T_{i}$ to local governments. The sum of these transfers is positive but some of them may be negative.

A close examination of the determination of a second best Pareto optimum suggests a two stage solution method. Let us rewrite the problem:

$$
\max _{C, X, G, Z_{w}} \sum_{i=1}^{n} \beta_{i} U^{i}\left(C_{i}, X_{i}, G_{i}, X_{i}, Z_{w}\right)
$$

under constraints

$$
\begin{aligned}
\left(C_{i}-Y_{i}\right)+X_{i} \frac{U_{X}^{i}\left(C_{i}, X_{i}, G_{i}, X_{i}, Z_{w}\right)}{U_{C}^{i}\left(C_{i}, X_{i}, G_{i}, X_{i}, Z_{w}\right)} & \geq 0, \quad i=1, \ldots, n \\
\sum_{i=1}^{n} X_{i} & =Z_{w} \\
\sum_{i=1}^{n}\left(C_{i}+X_{i}+G_{i}\right) & \leq \sum_{i=1}^{n} Y_{i}
\end{aligned}
$$

This problem is equivalent to a problem where we introduce new variables $\tau$ and $T_{i}$, $i=1, \ldots, n$ and impose constraints

$$
\begin{aligned}
C_{i}+G_{i}+(1+\tau) X_{i} & =Y_{i}+T_{i}, \quad i=1,2, \ldots, n \\
\sum_{i=1}^{n} T_{i} & \leq \tau Z_{w}
\end{aligned}
$$

instead of constraint (26). Indeed, taking into account (25), constraints (27) and (28) imply (26). Conversely, for any arbitrary $\tau$, consider a triplet $(C, X, G)$ satisfying (26). Define $T_{i}=C_{i}+G_{i}+(1+\tau) X_{i}-Y_{i}, \quad i=1,2, \ldots, n$. Summing implies $\sum T_{i}-\tau Z_{w}=$ $\sum\left(C_{i}+G_{i}+X_{i}-Y_{i}\right)$, which is negative as $(C, X, G)$ satisfies (26). Thus (28) is satisfied.

Let us now consider the maximization of social welfare under constraints (24), (25), (27) and (28). We may solve this problem in two stages.

First, the international environmental agency chooses $\tau$ and $T=\left(T_{1}, \ldots, T_{n}\right)$ and, given those $\tau$ and $T$, local governments look for $C_{i}, G_{i}, X_{i}$ which maximize their representative consumer's utility $U^{i}\left(C_{i}, X_{i}, G_{i}, X_{i}, Z_{w}\right)$ under constraints (24) and (27), and on the basis of their expectation of $Z_{w}$. This yields demand functions

$$
C_{i}=\chi^{i}\left(\tau, T_{i}, Z_{w}\right), \quad X_{i}=\xi^{i}\left(\tau, T_{i}, Z_{w}\right), \quad G_{i}=\gamma^{i}\left(\tau, T_{i}, Z_{w}\right)
$$

\footnotetext{
${ }^{3}$ It can alternatively control carbon emissions through a permits market.
} 
and the indirect utility function

$$
W^{i}\left(\tau, T_{i}, Z_{w}\right)
$$

For given $\tau$ and $T$, a perfect foresight equilibrium on $Z_{w}$ occurs, such that condition (25) is satisfied.

Second, the international environmental agency chooses the optimal $\tau$ and $T$. It solves the following problem:

$$
\max _{\tau, T, Z_{w}} \sum_{i=1}^{n} \beta_{i} W^{i}\left(\tau, T_{i}, Z_{w}\right)
$$

under constraints (26) and (28), (26) being now written as

$$
\sum_{i=1}^{n} \xi^{i}\left(\tau, T_{i}, Z_{w}\right)=Z_{w}
$$

The international environmental agency controls carbon emissions through a carbon tax. It distributes the revenues of the carbon tax as lump-sum transfers to local governments. These transfers may be negative in order to further subsidize some countries. A common carbon price is thus imposed at the world level. Each local government is still unable to finance its public goods provision through lump-sum taxation. But it is left free to choose its own way to levy funds and regulate local externalities. A subsidiarity principle is thus in effect.

Local governments are passive in the sense that they take as given the carbon tax $\tau$ as well as transfers $T_{i}$ s. Their problem is to maximize the utility of their representative consumer under their country budget constraint (14) and their incentive constraint (17). We do not make explicit the precise way they will implement this solution. The international environmental agency only takes into account the indirect utility function $W^{i}\left(\tau, T_{i}, Z_{w}\right)$ of each country and the demand of the polluting good $\xi^{i}\left(\tau, T_{i}, Z_{w}\right)$.

Proposition 4 A second best optimum may be implemented by an international environmental agency imposing a unique carbon tax and implementing intercountry lump-sum transfers.

This result shows how effective a uniform carbon price remains in a framework where each country faces second best constraints. Carbon taxation and intercountry transfers are the sole international coordination required to reach a social optimum. We also note that the proof does not depend on the form of the incentive constraints and is therefore quite general.

This proof provides a deeper explanation of the uniformity of the carbon tax. It shows that this uniformity property is in fact the consequence of a subsidiarity principle. The international environmental agency does not have to take into account the precise way in which each country regulates local externalities and finances the provision of its public goods. It may trust that this is achieved efficiently and only cares about the global climatic externality and the proper distribution of transfers. In some sense, the international regulation of the climatic externality remains a first best problem.

\section{A third best}

We now assume, as in Shiell (2003) and Sandmo (2005), that for political economy reasons, local governments are not ready to accept a smaller transfer than the amount of carbon 
taxes their citizens are paying to the environmental agency. Each local government actually receives a positive transfer from the environmental agency, as the country level of emissions is always positive, but there are no other intercountry transfers. Each country then has to satisfy constraint

$$
C_{i}+X_{i}+G_{i}=Y_{i}, \quad i=1,2, \ldots, n
$$

The problem is to maximize (2) under the resource constraints (29) and the additional incentive constraints (17). We name the second best optimum taking into account this additional constraint third best.

Proposition 5 A third best Pareto optimum is characterized by the following conditions:

$$
\begin{gathered}
\beta_{i}\left\{\left(U_{X}^{i}+\mu_{i} H_{X}^{i}\right)+\left(U_{Z}^{i}+\mu_{i} H_{Z}^{i}\right)-\left(U_{C}^{i}+\mu_{i} H_{C}^{i}\right)\right\}=-\sum \beta_{j}\left(U_{Z_{w}}^{j}+\mu_{j} H_{Z_{w}}^{j}\right), \quad i=1,2, \ldots, n \\
\frac{U_{G}^{i}+\mu_{i} H_{G}^{i}}{U_{C}^{i}+\mu_{i} H_{C}^{i}}=1, \quad i=1,2, \ldots, n \\
\sum_{j=1}^{n} \frac{U_{Z_{w}}^{j}+\mu_{j} H_{Z_{w}}^{j}}{\left(U_{C}^{j}+\mu_{j} H_{C}^{j}\right)-\left(U_{X}^{j}+\mu_{j} H_{X}^{j}\right)-\left(U_{Z}^{j}+\mu_{j} H_{Z}^{j}\right)}=1
\end{gathered}
$$

The three sets of conditions (30)-(32), together with the resource constraints (3) and incentive constraints (17) determine the third best optimum. Condition (31) governing the provision of public goods is the same as the one which appears in the second best optimum (condition (19)). Condition (32) is implied by the set of similar conditions (20) appearing in the second best solution. Indeed, (20) may be written as:

$$
\frac{\left(U_{X}^{i}+\mu_{i} H_{X}^{i}\right)+\left(U_{Z}^{i}+\mu_{i} H_{Z}^{i}\right)-\left(U_{C}^{i}+\mu_{i} H_{C}^{i}\right)}{U_{C}^{i}+\mu_{i} H_{C}^{i}}=-\sum_{j=1}^{n} \frac{U_{Z_{w}}^{j}+\mu_{j} H_{Z_{w}}^{j}}{U_{C}^{j}+\mu_{j} H_{C}^{j}}, \quad i=1,2, \ldots, n
$$

Dividing through by the common value of the LHS yields (32).

Consider now a particular allocation in the set of second best optima, where all transfers happen to be zero. Such an equilibrium usually exists and is unique. By definition it satisfies constraints (29) and therefore all constraints entering the definition of a third best optimum. We just showed that it satisfies all the optimality conditions for such an optimum. We thus confirm the rather natural property that, in general, one of the third best optima is a particular second best optimum. Both hypersurfaces in the space of utility levels will be tangent. This property has been stressed by Shiell (2003). Other third best optimum allocations are not second best optimum allocations. As we now show, this means that differentiated carbon taxes will be necessary to support them.

Corollary 6 In a third best setting, the carbon tax is generally not unique. The overall tax on the polluting good can be decomposed into three country-specific taxes:

$$
\theta_{i}=\phi_{i}+\psi_{i}+\tau_{i}
$$

with

$$
\phi_{i}=-\frac{U_{Z}^{i}+\mu_{i} H_{Z}^{i}}{U_{C}^{i}+\mu_{i} H_{C}^{i}}, \quad \psi_{i}=\mu_{i} \frac{\frac{U_{X}^{i}}{U_{C}^{i}} H_{C}^{i}-H_{X}^{i}}{U_{C}^{i}+\mu_{i} H_{C}^{i}}, \quad \tau_{i}=-\frac{\sum \beta_{j}\left(U_{Z_{w}}^{j}+\mu_{j} H_{Z_{w}}^{j}\right)}{\beta_{i}\left(U_{C}^{i}+\mu_{i} H_{C}^{i}\right)}
$$


The expressions of the Pigovian and the Ramsey tax rates $\phi_{i}$ and $\psi_{i}$ are the same as in the second best case. The carbon tax $\tau_{i}$ is now also country-specific. More precisely, we have

$$
\beta_{1}\left(U_{C}^{1}+\mu_{1} H_{C}^{1}\right) \tau_{1}=\ldots=\beta_{n}\left(U_{C}^{n}+\mu_{n} H_{C}^{n}\right) \tau_{n}
$$

Carbon prices are not equalized worldwide. Only weighted carbon prices are, the weight of country $i$ being $\beta_{i}\left(U_{C}^{i}+\mu_{i} H_{C}^{i}\right)$. This generalizes the similar relation which underlines the results of Chichilnisky and Heal (1994). As we take into account the provision of public goods, a new element $\mu_{i} H_{C}^{i}$ appears, which takes into account the cost of levying public funds in the country.

We may then restate the core of the Chichilnisky and Heal (1994) argument. In the case where intercountry transfers are feasible, condition (18) in Proposition 2 states that country weights are equalized. It follows that carbon prices, and abatement costs in the Chichilnisky and Heal (1994) set-up, are equalized. In the absence of intercountry transfers, the weights are not equalized and neither are the optimal carbon prices.

We may assume that social weights $\beta$ reflect the world regulator's aversion to inequality, which would automatically follow if we deduced them from the maximization of a symmetric international social utility function. A poorer country is then characterized by a higher $\beta_{i}$. This leads to reduction of inequality, but probably not its disappearance. A poorer country presumably remains poorer in the double sense that it has both a lower level of consumption, and therefore a higher marginal utility $U_{C}^{i}$ of consumption, and a higher cost of levying public funds, and therefore a higher $\mu_{i} H_{C}^{i}$ coefficient. We may thus safely assume that a poorer country is characterized by a larger weight $\beta_{i}\left(U_{C}^{i}+\mu_{i} H_{C}^{i}\right)$. The carbon price $\tau_{i}$ must then be lower in a poorer country. A smaller environmental effort must be required from poor countries, which is simply another part of the worldwide social optimization.

In order to compare our results with those obtained by Chichilnisky and Heal (1994), Shiell (2003) and Sandmo (2005), let us consider again our model in the absence of local externalities and public goods. We have $G_{i}=0$ and constraint (29) becomes $C_{i}+X_{i}=Y_{i}$. Comparison with the budget constraint (27) implies $T_{c i}=\theta_{i} X_{i}$, which is positive. The incentive constraint is not binding so that $\mu_{i}=0$ for all $i$, which implies $\psi_{i}=0$. The formulas in Proposition 5 are much simpler and become similar to the ones obtained by these authors. They have a first best flavor (see Table 2), whereas our analysis starts from a clear second best setting and is therefore more general.

\section{Conclusion}

It has been shown that the presence of public goods, restrictions on the redistributions of local tax revenues to local consumers, and the addition of a local component to the damage caused by global emissions does in principle not aggravate the problem of addressing the design of a second best optimal global pollution tax. An appropriate decomposition of the pollution tax can deal with the local aspect of pollution and with the constraint that only non-negative transfers can be given to local consumers. Hence, the global externality can be dealt with at the global level, through a uniform tax or a system of tradable permits. Nevertheless it is required that at the government levels international transfers can still be implemented. And it cannot be hoped that this problem can be solved. Indeed, it is uncertain whether governments will accept negative lump-sum transfers and even to receive less than what the country pays as carbon taxes. Chichilnisky and Heal (1994) 
have stressed that the impossibility of international redistribution should lead to reject the principle of equalizing worldwide abatement costs, that is having a uniform world carbon price. If we introduce constraints on intercountry transfers into our model, a uniform carbon price would not allow to reach the desired second best optimum. International differentiation of the price of carbon sometimes provides a useful instrument to reach a more equitable allocation. However, when it comes to climate change international transfers (whether monetary or technological or in terms of allocating permits) are in the picture already. The international community is aware of the fact that in reaching international agreements side payments are unavoidable.

\section{References}

Chichilnisky, G. and G. Heal (1994) "Who Should Abate Carbon Emissions? An International Perspective" Economics Letters 44, 443-449.

Lipsey, R. G. and K. Lancaster (1956-7) "The General Theory of Second Best" Review of Economic Studies 24, 11-32.

Ogawa, H. and D.E. Wildasin (2009) "Think Locally, Act Locally: Spillovers, Spillbacks, and Efficient Decentralized Policymaking" American Economic Review 99(4), 1206-17.

Sandmo, A. (1975) "Optimal Taxation in the Presence of Externalities" Swedish Journal of Economics 77, 86-98.

Sandmo, A. (2000) The Public Economics of the Environment, The Lindhal Lectures, Oxford University Press.

Sandmo, A. (2005) "Environmental Taxation and Revenue for Development", in A. B. Atkinson (ed.), New Sources of Development Finance, 112-130, Oxford University Press. Shiell, L. (2003) "Equity and Efficiency in International Markets for Pollution Permits" Journal of Environmental Economics and Management 46, 38-51.

Tirole, J. (2009) Politique climatique, une nouvelle architecture internationale, Rapport No 87 pour le Conseil d'Analyse Economique.

Verbon H. and C. Withagen (2010) "Do permit allocation matters?" CESifo Working Paper Series No. 3236.

\section{A Proof of Proposition 1}

Let $\lambda$ be the Lagrange multiplier associated to the resource constraint. Necessary conditions are:

$$
\begin{gathered}
\beta_{i} U_{C}^{i}=\lambda, \quad i=1,2, \ldots, n \\
\beta_{i} U_{G}^{i}=\lambda, \quad i=1,2, \ldots, n \\
\beta_{i}\left(U_{X}^{i}+U_{Z}^{i}\right)+\sum_{j=1}^{n} \beta_{j} U_{Z_{w}}^{j}=\lambda, \quad i=1,2, \ldots, n
\end{gathered}
$$

Conditions (34) and (35) yield condition (5) in Proposition 1.

Dividing both sides of (36) by $\lambda$, and noting from (34) that $\lambda$ may be taken equal to $\beta_{i} U_{C}^{i}$ or to any of the $\beta_{j} U_{C}^{j}$ yields

$$
\frac{U_{X}^{i}}{U_{C}^{i}}+\frac{U_{Z}^{i}}{U_{C}^{i}}+\sum_{j=1}^{n} \frac{U_{Z_{w}}^{j}}{U_{C}^{j}}=1, \quad i=1,2, \ldots, n
$$


which is condition (6) in Proposition 1.

\section{B Proof of Proposition 2 and Corollary 3}

Let $\lambda$ and $\widetilde{\mu}_{i}=\mu_{i} \beta_{i}$ be the Lagrange multipliers associated to constraints (3) and (17). $\mu_{i}$ will be interpreted as the cost of levying public funds in country $i$.

Assuming an interior solution $\left(C_{i}, X_{i}, G_{i}, Z_{i}, Z_{w}\right)>0$, we can write the optimality conditions as follows:

$$
\begin{gathered}
\beta_{i}\left(U_{C}^{i}+\mu_{i} H_{C}^{i}\right)=\lambda \\
\beta_{i}\left(U_{G}^{i}+\mu_{i} H_{G}^{i}\right)=\lambda \\
\beta_{i}\left(U_{X}^{i}+\mu_{i} H_{X}^{i}\right)+\beta_{i}\left(U_{Z}^{i}+\mu_{i} H_{Z}^{i}\right)+\sum_{j=1}^{n} \beta_{j}\left(U_{Z_{w}}^{j}+\mu_{j} H_{Z_{w}}^{j}\right)=\lambda
\end{gathered}
$$

(37) and (38) yield condition (19) in Proposition 2.

Dividing (39) by $\lambda$ and choosing from (37), in each place, the appropriate expression for $\lambda$ leads to (20) in Proposition 2. This equation may be written as

$$
\frac{U_{X}^{i}}{U_{C}^{i}}-1=\mu_{i} \frac{\frac{U_{X}^{i}}{U_{C}^{i}} H_{C}^{i}-H_{X}^{i}}{U_{C}^{i}+\mu_{i} H_{C}^{i}}-\frac{U_{Z}^{i}+\mu_{i} H_{Z}^{i}}{U_{C}^{i}+\mu_{i} H_{C}^{i}}-\sum_{j=1}^{n} \frac{U_{Z_{w}}^{j}+\mu_{j} H_{Z_{w}}^{j}}{U_{C}^{j}+\mu_{j} H_{C}^{j}}
$$

which is Corollary 3.

\section{Proof of Proposition 5 and Corollary 6}

Let $\lambda_{i}$ and $\widetilde{\mu}_{i}=\mu_{i} \beta_{i}$ be the Lagrange multipliers associated to constraints (29) and (17). Optimality conditions are, for $i=1,2, \ldots, n$,

$$
\begin{gathered}
\beta_{i}\left(U_{C}^{i}+\mu_{i} H_{C}^{i}\right)=\lambda_{i} \\
\beta_{i}\left(U_{G}^{i}+\mu_{i} H_{G}^{i}\right)=\lambda_{i} \\
\beta_{i}\left\{\left(U_{X}^{i}+\mu_{i} H_{X}^{i}\right)+\left(U_{Z}^{i}+\mu_{i} H_{Z}^{i}\right)\right\}=\lambda_{i}-\sum_{j=1}^{n} \beta_{j}\left(U_{Z_{w}}^{j}+\mu_{j} H_{Z}^{j}\right)
\end{gathered}
$$

(40) and (41) imply (31) in Proposition 5.

From (40) and (42) we have

$\beta_{i}\left\{\left(U_{X}^{i}+\mu_{i} H_{X}^{i}\right)+\left(U_{Z}^{i}+\mu_{i} H_{Z}^{i}\right)-\left(U_{C}^{i}+\mu_{i} H_{C}^{i}\right)\right\}=-\sum_{j=1}^{n} \beta_{j}\left(U_{Z_{w}}^{j}+\mu_{j} H_{Z}^{j}\right), \quad i=1,2, \ldots ., n$

The RHS does not depend on $i$ so that LHS expressions are equal accross $i$. Dividing through by this common value, and in particular dividing each term of the sum by the $j$-indexed expression of the LHS yields

$$
1=\sum_{j=1}^{n} \frac{U_{Z_{w}}^{j}+\mu_{j} H_{Z_{w}}^{j}}{\left(U_{C}^{j}+\mu_{j} H_{C}^{j}\right)-\left(U_{X}^{j}+\mu_{j} H_{X}^{j}\right)-\left(U_{Z}^{j}+\mu_{j} H_{Z}^{j}\right)}
$$


which is (32) in Proposition 5.

Condition (43) may be written as:

$$
\frac{U_{X}^{i}}{U_{C}^{i}}-1=\mu_{i} \frac{\frac{U_{X}^{i}}{U_{C}^{i}} H_{C}^{i}-H_{X}^{i}}{U_{C}^{i}+\mu_{i} H_{C}^{i}}-\frac{U_{Z}^{i}+\mu_{i} H_{Z}^{i}}{U_{C}^{i}+\mu_{i} H_{C}^{i}}-\frac{\sum \beta_{j}\left(U_{Z_{w}}^{j}+\mu_{j} H_{Z}^{j}\right)}{\beta_{i}\left(U_{C}^{i}+\mu_{i} H_{C}^{i}\right)}
$$

which is Corollary 6 . 